\begin{tabular}{|c|c|c|c|}
\hline \multirow{3}{*}{$\begin{array}{r}\text { Case Reports in } \\
\text { Gastroenterology }\end{array}$} & \multirow{2}{*}{\multicolumn{2}{|c|}{ Case Rep Gastroenterol 2015;9:126-131 }} & \\
\hline & & & \multirow[b]{2}{*}{ Oparger } \\
\hline & $\begin{array}{l}\text { DOI: } 10.1159 / 000382070 \\
\text { Publisnea onine:. Trlay } 1,2015\end{array}$ & $\begin{array}{l}\text { ( ) } 2015 \text { S. Karger AG, Basel } \\
1662-0631 / 15 / 0092-0126 \$ 39.50 / 0 \\
\text { www.karger.com/crg }\end{array}$ & \\
\hline & $\begin{array}{l}\text { This is an Open Access artic } \\
\text { Attribution-NonCommercial } 3.0 \\
\text { license), applicable to the onlin } \\
\text { commercial purposes only. }\end{array}$ & $\begin{array}{l}\text { the terms of the Creative Common } \\
\text { (CC BY-NC) (www.karger.com/OA } \\
\text { cle only. Distribution permitted for non }\end{array}$ & \\
\hline
\end{tabular}

\title{
Complete Endoscopic Submucosal Dissection of a Giant Rectal Villous Adenocarcinoma with Electrolyte Depletion Syndrome
}

\author{
Kazumasa Kure $^{a} \quad$ Masaya Kawai $^{\mathrm{a}}$ Shun Ishiyama $^{\mathrm{a}}$ Hirohiko Kamiyama $^{\mathrm{a}}$ \\ Yuichi Tomiki $^{\mathrm{a}}$ Kazuhiro Sakamoto $^{\mathrm{a}}$ Atsushi Arakawa $^{\mathrm{b}}$ Takashi Yao $^{\mathrm{b}}$ \\ Departments of ${ }^{a}$ Coloproctological Surgery and ${ }^{b}$ Human Pathology, Faculty of Medicine, \\ Juntendo University, Tokyo, Japan
}

\section{Key Words}

Rectal villous adenoma - Electrolyte depletion syndrome - Endoscopic submucosal dissection

\begin{abstract}
An 81-year-old female consulted a local physician due to diarrhea. Since general fatigue and body weight loss were observed, she was admitted for detailed examination and treatment. Colonoscopy revealed a circumferential giant tumor with a maximum diameter of $10 \mathrm{~cm}$ in the rectum, and biopsy findings indicated villous adenoma. The tumor secreted a large amount of mucus, and a diagnosis of electrolyte depletion syndrome causing electrolyte disorders was made. We performed endoscopic submucosal dissection (ESD) as a less invasive procedure. The tumor was so big that the procedure had to be completed in two separate steps and it took 1,381 $\mathrm{min}$ in total. The tumor was histologically diagnosed as welldifferentiated adenocarcinoma in high-grade adenoma located in the lower to upper rectum, invading into the mucosa without lymphatic or venous invasion. The stump of the resected specimen was negative for adenocarcinoma, however the horizontal stump was positive for adenoma. We administered steroid suppositories to prevent stenosis. After ESD, general fatigue and diarrhea disappeared and electrolyte disorders resolved. The patient had good clinical outcome without recurrence or stenosis.

(c) 2015 S. Karger AG, Basel
\end{abstract}

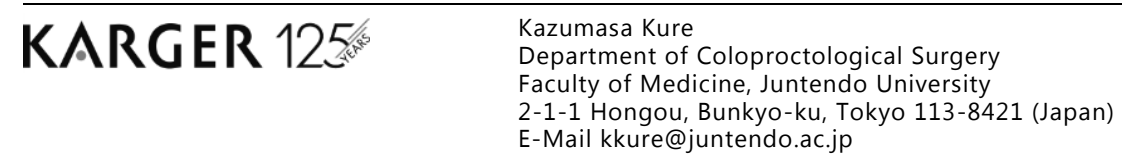


Kure et al.: Complete Endoscopic Submucosal Dissection of a Giant Rectal Villous Adenocarcinoma with Electrolyte Depletion Syndrome

\section{Introduction}

Villous tumor of the colon is a lesion with an apparently villous surface and is diagnosed macroscopically [1]. The area of predilection for villous tumor of the colon is the sigmoid colon and the rectum [2], and histologically the tumor is villous or tubulovillous adenoma and may be partly complicated by carcinoma. These tumors sometimes become large and promote excessive mucus secretion. Electrolyte disorders (loss of sodium, potassium and chloride), caused by the large amount of mucous diarrhea from giant villous tumors, are called electrolyte depletion syndrome [2]. It is said that a large quantity of mucinous secretion and reabsorption disorder may cause electrolyte disorder. Villous tumors with electrolyte depletion syndrome are often $\geq 10 \mathrm{~cm}$ in size and nearly circumferential. Because of their size, colon/rectal resection after correction of the electrolyte disorder is performed. There has been no report of endoscopic resection of villous tumors with electrolyte depletion syndrome.

We successfully treated a patient with a circumferential villous tumor of the rectum causing electrolyte depletion syndrome by endoscopic submucosal dissection (ESD). After ESD, general fatigue and diarrhea disappeared and electrolyte disorders resolved. The patient had good clinical outcome without recurrence or stenosis.

\section{Case Presentation}

The patient was an 81-year-old female with a primary complaint of diarrhea. She consulted a local physician in February 2013 due to diarrhea. Since general fatigue and a body weight loss of $3 \mathrm{~kg}$ within 5 months were observed, she was admitted for detailed examination and treatment. On blood tests, blood urea nitrogen was $58.7 \mathrm{mg} / \mathrm{dl}$ and creatinine was $1.02 \mathrm{mg} / \mathrm{dl}$, indicating kidney dysfunction; sodium was $126 \mathrm{mEq} / \mathrm{l}$, potassium was $2.5 \mathrm{mEq} / \mathrm{l}$ and chloride was $79 \mathrm{mEq} / \mathrm{l}$, showing electrolyte disorders. Concerning tumor markers, carcinoembryonic antigen was elevated at $6.6 \mathrm{ng} / \mathrm{ml}$ (table 1). Colonoscopy revealed a circumferential laterally spreading tumor with a maximum diameter of $10 \mathrm{~cm}$ in the rectum. Since biopsy findings indicated villous adenoma, the patient was referred to our hospital for endoscopic treatment.

On admission we observed mild anemia with a hemoglobin of $10.7 \mathrm{~g} / \mathrm{dl}$. The electrolyte levels had been corrected by the previous physician and were in the normal ranges. Colonoscopy revealed a circumferential villous tumor of the rectum with a maximum diameter of $10 \mathrm{~cm}$ (fig. 1a). Narrow-band imaging magnifying endoscopy revealed meshed capillary vessels, and the tumor was classified as type IIIA [3]. It secreted a large amount of mucus, and a diagnosis of electrolyte depletion syndrome causing electrolyte disorders was made.

Since submucosal invasion was judged to be negative, sufficient informed consent was obtained from the patient and her family, and ESD was carried out in late June. The circumferential lesion was dissected annularly. There was marked hemorrhage, and hemostasis was difficult during the procedure. After about $12 \mathrm{~h}$ (727 min), when about half of the tumor had been dissected, ESD was temporarily suspended in consideration of the stress to the patient and concentration of the endoscopist. On the next day, ESD could not be continued because there was no vacancy in the schedule of the endoscopy room. ESD was resumed on the following day, $36 \mathrm{~h}$ after its suspension, and the tumor was removed en bloc with dissection of the remaining half (fig. 1b). The total duration of the procedure was 1,381 min. Since circumferential dissection was performed, steroid (triamcinolone acetonide) was topically injected into the submucosa as a measure to prevent stenosis. 
Kure et al.: Complete Endoscopic Submucosal Dissection of a Giant Rectal Villous Adenocarcinoma with Electrolyte Depletion Syndrome

Histopathological examination revealed that the resected specimen was a circumferential tumor measuring $12.7 \times 11.5 \mathrm{~cm}$ and was mostly tubulovillous adenoma, but partially moderately differentiated adenocarcinoma. The histopathological diagnosis was well-differentiated adenocarcinoma in high-grade adenoma located in the lower to upper rectum, invading into the mucosa without lymphatic or venous invasion, with a stump negative for adenocarcinoma and positive for adenoma.

Oral nutrition was resumed on the 2 nd postoperative day, and the patient was discharged on the 8th postoperative day. Steroid (betamethasone) suppositories were administered at $1 \mathrm{mg} /$ day. After discharge, general fatigue and diarrhea present before ESD disappeared, and electrolyte disorders resolved (table 1). Colonoscopy 4 months after ESD showed shrinking of the dissected surface, and no marked constriction or remnant of the tumor was noted (fig. 1c). The administration of steroid suppositories was discontinued at this point. On colonoscopy 12 months after ESD, the dissected surface was covered by regenerated mucosa, and no recurrence or stenosis was noted (fig. 1d).

\section{Discussion}

According to the definition by Muto and Adachi [1], villous tumor of the colon is a lesion with an apparently villous surface and is diagnosed macroscopically. Histologically, the tumor is villous or tubulovillous adenoma and may be partly complicated by carcinoma. The symptoms of villous tumor include diarrhea, mucus discharge and bloody stools. Electrolyte disorders caused by mucous diarrhea are called electrolyte depletion syndrome and were first reported in 1954 by McKittrick and Wheelock [4]. The frequency of electrolyte disorders caused by villous tumor is $0.76-2.4 \%$, and the condition is relatively rare $[5,6]$. Sasaki et al. [2] reported (1) frequent occurrence in elderly people, (2) long duration of illness, (3) frequent involvement of the rectum or sigmoid colon, (4) frequent extension to a length of $\geq 10 \mathrm{~cm}$, (5) marked diarrhea and (6) frequent complication by carcinoma as characteristics of villous tumor of the colon causing electrolyte depletion syndrome. Our patient showed (1) and (3)-(6) of these characteristics. Niwa et al. [7] reviewed 64 Japanese cases in the literature and reported that villous tumors were large, with a maximum diameter of 4-26 cm (mean $13.9 \mathrm{~cm}$ ), were nearly circumferential and were complicated by carcinoma in $72.4 \%$ of those who developed electrolyte depletion syndrome.

Concerning treatment, complete resection of the tumor is necessary after the correction of dehydration and electrolyte disorders, but the disease is often mucosal tumor or shows no complicating carcinoma, and there is a report that a procedure similar to that for advanced colon cancer may be overtreatment [8]. In our patient, carcinoma was not detected by biopsy, and ESD was performed as a less invasive procedure.

ESD is a treatment that permits en bloc resection of large lesions, which used to be difficult to resect endoscopically, and allows detailed histopathological evaluation $[9,10]$. There have been reports of ESD performed for lesions $>10 \mathrm{~cm}$ in diameter [11-13]. Also, stenosis has been reported to occur less frequently even after circumferential dissection of the colon by ESD because of the intraintestinal pressure and peristalsis [14]. Mitani et al. [14] administered betamethasone suppositories at $1 \mathrm{mg} /$ day for two rectal lesions for 8 weeks after circumferential dissection and reported no marked postoperative stenosis. However, Yamada et al. [15] reported that they treated a patient with an upper rectum to rectosigmoid circumferential laterally spreading tumor $10 \mathrm{~cm}$ in diameter by ESD, noted stenosis on the 23rd postoperative day and performed endoscopic balloon dilatation. In our patient, we administered steroid (triamcinolone acetonide) topically to the submucosa after dissection as a 
Kure et al.: Complete Endoscopic Submucosal Dissection of a Giant Rectal Villous Adenocarcinoma with Electrolyte Depletion Syndrome

measure to prevent stenosis, followed by a 4-month treatment with steroid suppositories, and could avoid stenosis. Therefore, after circumferential dissection, it is considered useful to prophylactically administer steroid with short-term observation and attempt endoscopic balloon dilatation if stenosis is observed.

Mitani et al. [14] evaluated 34 patients who underwent extensive ESD of a tumor $\geq 10 \mathrm{~cm}$ in maximum diameter and observed that ESD, which is less invasive than surgical resection, is also advantageous for functional preservation, because the endoscope could be manipulated readily in the rectum, the risk of peritonitis due to perforation was low and colostomy could be avoided. In our patient, ESD extended over 2 days, but the lesion could be completely resected without the need to construct a stoma. Postoperatively, electrolyte disorders were resolved, symptoms were alleviated, and no recurrence of cancer or stenosis was noted. It is still necessary to improve the technique of ESD in order to shorten the time needed for the procedure. However, less invasive treatment by ESD should still be considered for colorectal adenoma and mucosal carcinoma, even if the procedure takes a long time.

In conclusion, a patient with a large colorectal carcinoma showing electrolyte depletion syndrome was successfully treated by ESD without recurrence or stenosis.

\section{References}

1 Muto T, Adachi K: Villous tumor of the large bowel - definition and treatment (in Japanese). Stomach Intestine 1986;21:1365-1372.

2 Sasaki T, Oomoto F, Maruyama M: Thirty-seven cases of villous adenoma of the large bowel. Stomach Intestine 1982;17:1151-1160.

-3 Ikematsu H, Matsuda T, Emura F, Saito Y, Uraoka T, Fu KI, Kaneko K, Ochiai A, Fujimori T, Sano Y: Efficacy of capillary pattern type IIIA/IIIB by magnifying narrow band imaging for estimating depth of invasion of early colorectal neoplasms. BMC Gastroenterol 2010;10:33.

4 McKittrick LS, Wheelock FC: Carcinoma of the colon. 1954. Dis Colon Rectum 1997:40:1494-1495.

5 Jahadi MR, Baldwin A: Villous adenoma of the colon and rectum. Am J Surg 1975;130:729-732.

6 Schapiro S: Villous papilloma of the rectum and colon, selective therapy and a surgico-pathologic classification of 165 cases. Arch Surg 1965;91:362-370.

7 Niwa K, Nagayasu K, Takahashi M, Goto M, Tomiki Y, Sakamoto K: A case of villous tumor of the rectum with electrolyte depletion syndrome. J Jpn Coll Surg 2012;37:298-302.

8 Yanabu N, Sato T: A case of villous tumor of the rectum with cancer change and electrolyte depletion syndrome. J Jpn Surg Assoc 2004;65:735-738.

-9 Yahagi N, Fujishiro M, Imagawa A, Kakushima N, Iguchi M, Omata M: Endoscopic submucosal dissection for the reliable en bloc resection of colorectal mucosal tumors. Dig Endosc 2004;16(suppl 1):S89-S92.

-10 Kuroki Y, Hoteya S, Mitani T, Yamashita S, Kikuchi D, Fujimoto A, Matsui A, Nakamura M, Nishida N, Iizuka T, Yahagi N: Endoscopic submucosal dissection for residual/locally recurrent lesions after endoscopic therapy for colorectal tumors. J Gastroenterol Hepatol 2010;25:1747-1753.

11 Fujishiro M, Yahagi N, Nakamura M, Kakushima N, Kodashima S, Ono S, Kobayashi K, Hashimoto T, Yamamichi N, Tateishi A, Shimizu Y, Oka M, Ogura K, Kawabe T, Ichinose M, Omata M: Endoscopic submucosal dissection for rectal epithelial neoplasia. Endoscopy 2006;38:493-497.

-12 Fujishiro M, Yahagi N, Kakushima N, Kodashima S, Ichinose M, Omata M: Successful endoscopic en bloc resection of a large laterally spreading tumor in the rectosigmoid junction by endoscopic submucosal dissection. Gastrointest Endosc 2006;63:178-183.

13 Antillon MR, Bartalos CR, Miller ML, Diaz-Arias AA, Ibdah JA, Marshall JB: En bloc endoscopic submucosal dissection of a $14-\mathrm{cm}$ laterally spreading adenoma of the rectum with involvement to the anal canal: expanding the frontiers of endoscopic surgery (with video). Gastrointest Endosc 2008;67:332-337.

14 Mitani T, Yamada A, Domon K, Furuhata T, Yamashita S, Kikuchi D, Nakamura M, Matsui A, Ogawa 0, Iizuka T, Hoteya S, Kaise M: Management after colorectal ESD for circumferential extensive tumors of more than three quarters. Endosc Dig 2013;25:477-482.

15 Yamada S, Hirano K, Waseda Y, Inagaki S, Miwa K, Kaneko Y, Gotoh Y, Doyama H, Katayanagi K, Kuruyama H: Case report of a rectal stenosis after endoscopic submucosal dissection of a giant rectal tumor.

Gastroenterol Endosc 2010;52:1421-1425. 
Kure et al.: Complete Endoscopic Submucosal Dissection of a Giant Rectal Villous Adenocarcinoma with Electrolyte Depletion Syndrome

Table 1. Blood test results

\begin{tabular}{lll}
\hline & Pre-ESD & Post-ESD \\
\hline $\mathrm{WBC}, \times 10^{6} / \mathrm{l}$ & 6,600 & 4,400 \\
$\mathrm{RBC}, \times 10^{12} / \mathrm{l}$ & 4.22 & 3.15 \\
$\mathrm{Hb}, \mathrm{g} / \mathrm{dl}$ & 12.9 & 10.1 \\
$\mathrm{Hct}, \%$ & 38.5 & 31.6 \\
$\mathrm{Plt}, \times 10^{9} / \mathrm{l}$ & 13.9 & 15.2 \\
$\mathrm{AST}, \mathrm{IU} / \mathrm{l}$ & 21 & 13 \\
$\mathrm{ALT}, \mathrm{IU} / \mathrm{l}$ & 11 & 7 \\
$\mathrm{TP}, \mathrm{g} / \mathrm{dl}$ & 8.3 & 6.3 \\
$\mathrm{BUN}, \mathrm{mg} / \mathrm{dl}$ & 58.7 & 19.0 \\
$\mathrm{Cre}, \mathrm{mg} / \mathrm{dl}$ & 1.02 & 0.42 \\
$\mathrm{Na}, \mathrm{mEq} / \mathrm{l}$ & 126 & 141 \\
$\mathrm{~K}, \mathrm{mEq} / \mathrm{l}$ & 2.5 & 4.6 \\
$\mathrm{Cl}, \mathrm{mEq} / \mathrm{l}$ & 79 & 106 \\
$\mathrm{CRP}, \mathrm{mg} / \mathrm{dl}$ & 0.09 & 0.5 \\
$\mathrm{CEA}, \mathrm{ng} / \mathrm{ml}$ & 6.6 & 2.2 \\
\hline
\end{tabular}




\begin{tabular}{|c|c|c|}
\hline \multirow{3}{*}{$\begin{array}{r}\text { Case Reports in } \\
\text { Gastroenterology }\end{array}$} & \multirow{2}{*}{\multicolumn{2}{|c|}{ Case Rep Gastroenterol 2015;9:126-131 }} \\
\hline & & \\
\hline & DOI: $10.1159 / 000382070$ & $\begin{array}{l}\text { (c) } 2015 \text { S. Karger AG, Basel } \\
\text { www.karger.com/crg }\end{array}$ \\
\hline
\end{tabular}

Adenocarcinoma with Electrolyte Depletion Syndrome
Adio

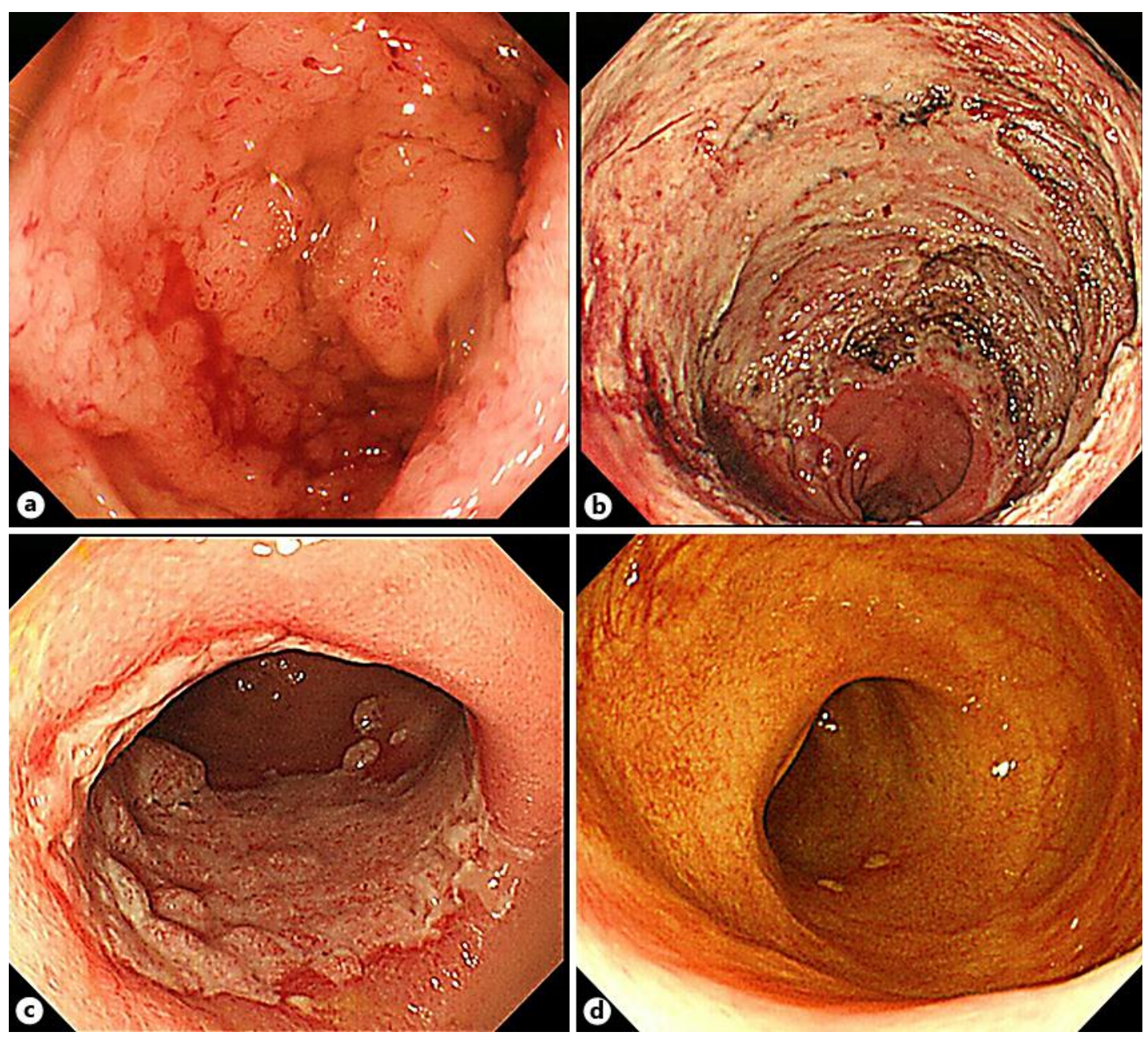

Fig. 1. a Colonoscopy showed a circumferential laterally spreading tumor (granular type) with a maximum diameter of about $10 \mathrm{~cm}$ in the rectum. b Annular circumferential dissection was performed. c Colonoscopic findings 4 months after ESD. The dissected surface had shrunk and no marked stenosis or residual tumor was noted. $\mathbf{d}$ Colonoscopic findings 12 months after ESD. The dissected surface was covered by regenerated mucosa and no recurrence or stenosis was noted. 